\title{
Review Article \\ Ginger and Its Constituents: Role in Prevention and Treatment of Gastrointestinal Cancer
}

\author{
Sahdeo Prasad and Amit K. Tyagi \\ Cytokine Research Laboratory, Department of Experimental Therapeutics, The University of Texas MD Anderson Cancer Center,
} Houston, TX 77030, USA

Correspondence should be addressed to Sahdeo Prasad; spbiotech@gmail.com

Received 29 October 2014; Revised 20 January 2015; Accepted 16 February 2015

Academic Editor: Eldon A. Shaffer

Copyright (C) 2015 S. Prasad and A. K. Tyagi. This is an open access article distributed under the Creative Commons Attribution License, which permits unrestricted use, distribution, and reproduction in any medium, provided the original work is properly cited.

\begin{abstract}
Gastrointestinal (GI) cancer, a cancer of different organs of the digestive system, is one of the most common cancers around the world. The incidence and death rate of some of these cancers are very high. Although a large variety of chemotherapeutic agents have been introduced since the last few decades to combat GI cancer, most of them are very expensive and have side effects. Therefore, the compounds derived from natural sources, which are considered to be safe and cost effective, are needed. Ginger (Zingiber officinale) is one of the most widely used natural products consumed as a spice and medicine for treating nausea, dysentery, heartburn, flatulence, diarrhea, loss of appetite, infections, cough, and bronchitis. Experimental studies showed that ginger and its active components including 6-gingerol and 6-shogaol exert anticancer activities against GI cancer. The anticancer activity of ginger is attributed to its ability to modulate several signaling molecules like NF- $\kappa$ B, STAT3, MAPK, PI3K, ERK1/2, Akt, TNF- $\alpha$, COX-2, cyclin D1, cdk, MMP-9, survivin, cIAP-1, XIAP, Bcl-2, caspases, and other cell growth regulatory proteins. In this review, the evidences for the chemopreventive and chemotherapeutic potential of ginger extract and its active components using in vitro, animal models, and patients have been described.
\end{abstract}

\section{Introduction}

The gastrointestinal (GI) tract is one of the important parts of the body. This tract starts from the mouth, includes esophagus, stomach, small and large intestine, and rectum, and finally ends with anus. The human GI tract is a single tube which is approximately nine meters long in relaxed condition [1]. Disorder in any part of the GI tract results in various malfunctions such as diseases of digestive system and cancer.

GI cancer is defined as the cancer of organs of the digestive system including the esophagus, gallbladder, liver, pancreas, stomach, small intestine, large intestine, rectum, and anus (Figure 1) [2]. The common risk factors for GI cancer include infection, smoking, drinking alcohol, high fat diet, age, race, gender, family history, and geographical location. The occurrence of GI cancer is very high in developed countries. In the United States, GI cancer accounts to 20 percent of all newly diagnosed cancer cases. Among different GI cancers, colorectal cancer is the most common cancer and is the second leading cause of death [3].
Accumulated evidences revealed that changing lifestyle could prevent all these cancers. The major change in lifestyle which proves beneficial includes avoiding tobacco, increased ingestion of fruits and vegetables, moderate use of alcohol, caloric restriction, exercise, minimal meat consumption, intake of whole grains, proper vaccinations, and regular health checkups. The link between healthy diet and cancer has been revealed in numerous studies [4-7]. An inverse association between the consumption of fruits and vegetables and cancer risk was evident by an epidemiological study in Netherlands. It has been found that the consumption of 21 vegetables and 9 fruits decreased the tumor growth in urothelial cancer patients [8]. It has also been reported that Asians have lower incidence of cancer than the residents of Western countries, and the rate increases substantially among Asians who have migrated to the West (http://www.dietandcancerreport.org/?p=ER). Consumption of diet rich in plant products may be one of the important reasons for the low incidence of cancer in Asia. A wide variety of natural products containing anticancer properties have been 


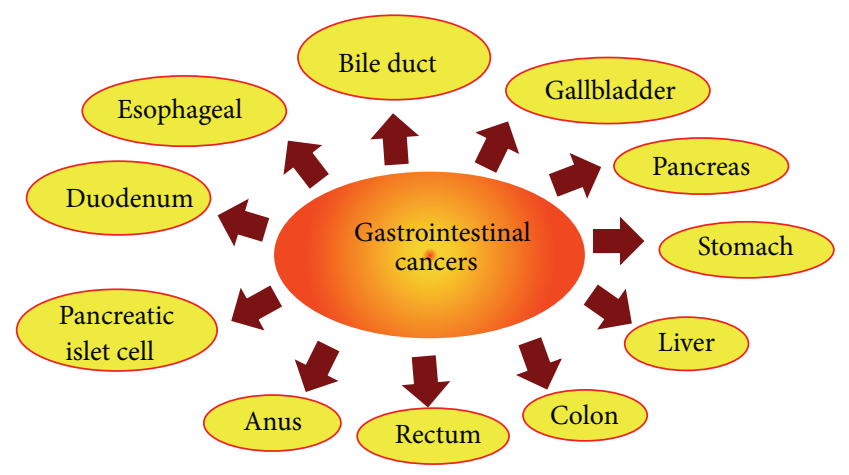

FIGURE 1: Different cancer types which are categorized under gastrointestinal cancer.

reported in the literature. In this paper, the role of ginger and its active ingredients against GI cancer have been discussed as it has worldwide consumption as a spice.

\section{Ginger and Its Constituents}

Ginger (Zingiber officinale), a member of the Zingiberaceae family, is a popular spice used globally especially in most of the Asian countries [9]. Chemical analysis of ginger shows that it contains over 400 different compounds. The major constituents in ginger rhizomes are carbohydrates (50-70\%), lipids (3-8\%), terpenes, and phenolic compounds [10]. Terpene components of ginger include zingiberene, $\beta$-bisabolene, $\alpha$-farnesene, $\beta$-sesquiphellandrene, and $\alpha$ curcumene, while phenolic compounds include gingerol, paradols, and shogaol (Figure 2). These gingerols (23-25\%) and shogaol (18-25\%) are found in higher quantity than others. Besides these, amino acids, raw fiber, ash, protein, phytosterols, vitamins (e.g., nicotinic acid and vitamin A), and minerals are also present $[11,12]$.

The aromatic constituents include zingiberene and bisabolene, while the pungent constituents are known as gingerols and shogaols [58]. Other gingerol- or shogaol-related compounds (1-10\%), which have been reported in ginger rhizome, include 6-paradol, 1-dehydrogingerdione, 6- gingerdione and 10-gingerdione, 4- gingerdiol, 6-gingerdiol, 8gingerdiol, and 10-gingerdiol, and diarylheptanoids [59,60]. The characteristic odor and flavor of ginger are due to a mixture of volatile oils like shogaols and gingerols [61].

\section{Use of Ginger as a Traditional Medicine}

Ginger has been used as a spice as well as medicine in India and China since ancient times. It was also known in Europe from the 9th century and in England from the 10th century for its medicinal properties [62]. Native Americans have also used wild ginger rhizome to regulate menstruation and heartbeat. Ginger is thought to act directly on the gastrointestinal system to reduce nausea. Therefore, it is used to prevent nausea resulting from chemotherapy, motion sickness, and surgery [63]. Ginger is known as a popular remedy for nausea

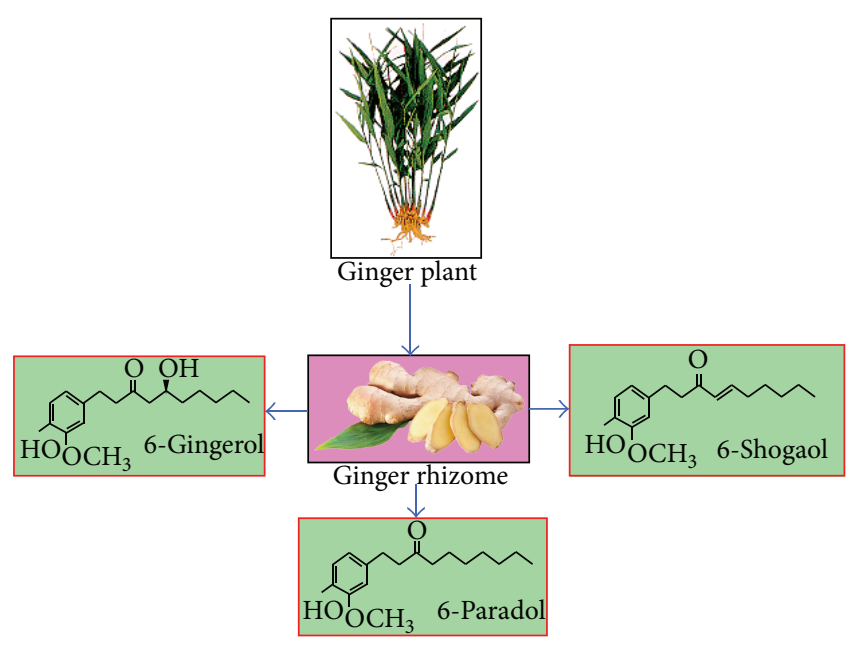

FIGURE 2: Ginger, ginger rhizome, and its major active components: 6-gingerol, 6-shogaol, and 6-paradol.

during pregnancy [11]. Ginger is also used to treat various types of other GI problems like morning sickness, colic, upset stomach, gas, bloating, heartburn, flatulence, diarrhea, loss of appetite, and dyspepsia (discomfort after eating). According to Indian Ayurvedic medicinal system, ginger is recommended to enhance the digestion of food [59].

Besides these, ginger has been reported as a pain relief for arthritis, muscle soreness, chest pain, low back pain, stomach pain, and menstrual pain. It can be used for treating upper respiratory tract infections, cough, and bronchitis. As an antiinflammatory agent, it is recommended for joint problems [12]. Fresh juice of ginger has been shown to treat skin burns. Active component of ginger is used as a laxative and antacid medication. It is also used to warm the body for boosting the circulation and lowering high blood pressure. Because of its warming effect, ginger acts as antiviral for treatment of cold and flu [64]. Ginger is also used as a flavoring agent in foods and beverages and as a fragrance in soaps and cosmetics [65].

\section{Role of Ginger and Its Constituents in Prevention and Treatment of Gastrointestinal Cancer}

Evidences from in vitro, animal, and epidemiological studies suggest that ginger and its active constituents suppress the growth and induce apoptosis of variety of cancer types including skin, ovarian, colon, breast, cervical, oral, renal, prostate, gastric, pancreatic, liver, and brain cancer. These properties of ginger and its constituents could be associated with antioxidant, anti-inflammatory, and antimutagenic properties as well as other biological activities [66]. In this review, focus has been laid solely on GI cancers to describe whether ginger and its active components exhibit chemopreventive and chemotherapeutic potential. The in vitro (Table 1), in vivo (Table 2), and clinical effects (Table 3 ) of ginger have also been described. 
TABLE 1: In vitro effects of ginger and its constituents against various GI cancer models.

\begin{tabular}{|c|c|c|}
\hline Cancer & Effects & Reference \\
\hline \multicolumn{3}{|l|}{ Liver } \\
\hline HepG2 & Induce apoptosis by activation of caspase- 3 & {$[13]$} \\
\hline Liver microsomes & $\begin{array}{l}\text { Inhibit CYP450, 1-aminobenzotriazole, and aldo-keto reductase } \\
\text { Prevent the formation of M14 and M15 and 18 } \beta \text {-glycyrrhetinic acid }\end{array}$ & {$[14]$} \\
\hline SMMC-7721 & Inhibit the phosphorylation of eIF $2 \alpha$ and triggered apoptosis & {$[15]$} \\
\hline HeoG2 & $\begin{array}{l}\text { Release cathepsin D and subsequently cytochrome c } \\
\text { Induce apoptosis and intracellular ROS generation and reduced glutathione }\end{array}$ & {$[16]$} \\
\hline $\mathrm{PC} 12$ & Inhibit xanthine oxidase and $\mathrm{H}_{2} \mathrm{O}_{2}$-induced damage & {$[17]$} \\
\hline HepG2/Hep3B & $\begin{array}{l}\text { Decrease the MMP-9 activity and increase the TIMP-1 expression } \\
\text { Decrease urokinase-type plasminogen activator activity in Hep3B cells }\end{array}$ & {$[18]$} \\
\hline Hep-2 & Dose-dependently suppress cell proliferation & {$[19]$} \\
\hline Mahlavu cells & Activate caspases $3 / 7$ resulting in the DNA fragmentation & {$[20]$} \\
\hline RL34 & Activate the Nrf2/ARE-dependent detoxification pathway & {$[21]$} \\
\hline \multicolumn{3}{|l|}{ Pancreas } \\
\hline $\mathrm{PaCa}$ & Inhibit mRNA expression and protein secretion of angiogenic factors and NF- $\kappa \mathrm{B}$ activity & {$[22]$} \\
\hline PANC-1, BxPC & $\begin{array}{l}\text { Downregulate of NF- } \kappa \text { B signaling and cell survival regulators including COX-2, cyclin D1, } \\
\text { survivin, cIAP-1, XIAP, Bcl-2, and MMP-9 and sensitize to gemcitabine }\end{array}$ & {$[23]$} \\
\hline$\beta$-cell (INS-1E) & Induce $\mathrm{Ca}^{2+}$ signals in the $\beta$-cell by activating the TRPV1 channels & {$[24]$} \\
\hline PANC-1 & $\begin{array}{l}\text { Decrease invasion and metastasis and NF- } \kappa \text { B translocation via downregulation of the ERK } \\
\text { pathway }\end{array}$ & [25] \\
\hline PANC-1 & Upregulate p53, p21 proteins level and ROS production & {$[26]$} \\
\hline HPAC, BxPC-3 & Decrease cyclin A, Cdk, Rb phosphorylation, and p53 expression & {$[27]$} \\
\hline \multicolumn{3}{|l|}{ Gastric Cancer } \\
\hline HUVE-AGS & Inhibit cell proliferation, VEGF expression, and NF- $\kappa \mathrm{B}$ activity & {$[28]$} \\
\hline kBZ Jurkat & inhibit COX-2 activation and reduce $H$. pylori-induced inflammation & {$[29]$} \\
\hline HGC/AGS/and KATO III & $\begin{array}{l}\text { Inhibit TRAIL-induced NF- } \kappa \mathrm{B} \text { activation, cIAP1 expression } \\
\text { Increase TRAIL-induced caspase- } 3 / 7 \text { activation }\end{array}$ & {$[30]$} \\
\hline JB6 & Inhibit the growth of all Helicobacter pylori strains & {$[31]$} \\
\hline \multicolumn{3}{|l|}{ Colorectal } \\
\hline Caco-2 & Inhibit cytochrome P450 enzymes (CYP1A2 and CYP2C8) & {$[32]$} \\
\hline HCT116 & Act as antiproliferative agents and enhance the chemotherapeutic effect of 5-FU & {$[33]$} \\
\hline COLO 205 & $\begin{array}{l}\text { Induce apoptosis, cytochrome c release, caspase activation, and DNA fragmentation } \\
\text { Upregulate the Bax, Fas, and FasL and downregulate Bcl-2 and Bcl-XL proteins }\end{array}$ & {$[34]$} \\
\hline HCT116 & $\begin{array}{l}\text { Suppress cyclin D1 expression and induced NAG-1 expression } \\
\text { Inhibit beta-catenin, PKC-epsilon, and GSK-3 beta pathways }\end{array}$ & {$[35]$} \\
\hline HCT116 & $\begin{array}{l}\text { Potentiate TRAIL-induced apoptosis and upregulate of TRAIL death receptors (DR-4/-5) } \\
\text { Inhibit extracellular signal-regulated kinase } 1 / 2 \text { and p38-MAPK }\end{array}$ & [36] \\
\hline \multicolumn{3}{|l|}{ Cholangiocarcinoma } \\
\hline CCA (CL-6) & Upregulate MDR1 and MRP3 genes & {$[37]$} \\
\hline KIM-1 & Induce programmed cell death through endonuclease activation and induction of p53 & [38] \\
\hline KMC-1 & caspase 3 activation, potentiate free-radical formation and accumulation of sphinganine & \\
\hline
\end{tabular}

CYP450, cytochrome P450; eIF2 $\alpha$, eukaryotic initiation factor 2 alpha; ROS, reactive oxygen species; TIMP-1, tissue inhibitor of metalloproteinase 1; Nrf2, nuclear factor (erythroid-derived 2)-like 2; ARE, antioxidant response element; COX-2, cyclooxygenase-2; cIAP-1, cellular inhibitor of apoptosis protein-1; XIAP, X-linked inhibitor of apoptosis protein; MMP-9, matrix metallopeptidase-9; NF- $\kappa$ B, nuclear factor kappaB; ERKs, extracellular-signal-regulated kinase; $\mathrm{Rb}$, retinoblastoma; VEGF, vascular endothelial growth factor; TRAIL, TNF-related apoptosis-inducing ligand; NAG-1, nonsteroidal anti-inflammatory drug(NSAID-) activated gene-1; PKC, protein kinase C; GSK-3 beta, glycogen synthase kinase-3 beta; MDR1, multidrug resistance gene-1; MRP3; multidrug resistance protein 3 . 
TABLE 2: In vivo effects of ginger and its constituents against various GI cancer models.

\begin{tabular}{|c|c|c|}
\hline Cancer & Effects & Reference \\
\hline Liver & Exhibit hepatoprotective activity against alcoholic fatty liver disease in C57BL/6 mice & [39] \\
\hline \multirow[t]{2}{*}{ Liver } & $\begin{array}{l}\text { Increase superoxide dismutase and glutathione reductase level in blood } \\
\text { Increase glutathione-S-transferase, glutathione peroxidase, and superoxide dismutase enzymes in liver }\end{array}$ & [40] \\
\hline & $\begin{array}{l}\text { Reduce carrageenan-, dextran-, and formalin- induced chronic inflammation } \\
\text { Reduce acetic acid induced writhing movements }\end{array}$ & [41] \\
\hline Liver & $\begin{array}{l}\text { Decrease the hepatic content of metallothionein and endostatin in Wister Albino rats } \\
\text { Increase the growth factors induced by the carcinogen }\end{array}$ & \\
\hline \multirow[t]{2}{*}{ Liver } & $\begin{array}{l}\text { Protect the rat liver from the carcinogenic effects of DEN and AAF } \\
\text { Increase Bax and decrease Bcl-2 protein expression }\end{array}$ & [42] \\
\hline & $\begin{array}{l}\text { Downregulate serum alanine transaminase, aspartate transaminase, alkaline phosphatase, and } \\
\text { alpha-fetoprotein }\end{array}$ & {$[23]$} \\
\hline Pancreatic & $\begin{array}{l}\text { Downregulate NF- } \kappa \text { B signaling and cell survival regulators and sensitize to gemcitabine treatment in } \\
\text { pancreatic cancer xenografted mice }\end{array}$ & \\
\hline Liver & $\begin{array}{l}\text { Inhibit CYP450, 1-aminobenzotriazole, and aldo-keto reductase liver microsomes of rats } \\
\text { and prevent the formation of M14 and M15 and 18 } \beta \text {-glycyrrhetinic acid }\end{array}$ & {$[14]$} \\
\hline Liver & Downregulate NF- $\kappa$ B and TNF- $\alpha$ in Wistar rats with liver cancer & {$[43]$} \\
\hline Liver & Reduce SOD activity and MDA level and increase catalase activity in liver of Wistar rats & {$[44]$} \\
\hline Colon & Decrease the incidence and number of tumors in colon of Wistar rats & [45] \\
\hline Gastric & Inhibit the expression of the chemokines and TNF- $\alpha$ in gastric cancer of rat model & [46] \\
\hline Gastric & Reverse cisplatin-induced delay in gastric emptying in rats & [47] \\
\hline Colon & $\begin{array}{l}\text { Decrease the fecal bile acids, neutral sterols, tissue cholesterol, HMG CoA reductase, free fatty acids, } \\
\text { triglycerides, phospholipase A, and phospholipase C in colon }\end{array}$ & {$[48]$} \\
\hline Colon & $\begin{array}{l}\text { Decrease the incidence and number of tumors in colon as well as the activity of beta-glucuronidase and } \\
\text { mucinase }\end{array}$ & {$[49]$} \\
\hline CCA & $\begin{array}{l}\text { Exhibit anti-inflammatory, antihypertensive, and antiulcer activities in CCA xenograft nude mouse } \\
\text { model }\end{array}$ & {$[37]$} \\
\hline Colon & Block the azoxymethane-induced intestinal carcinogenesis in rats & {$[50]$} \\
\hline
\end{tabular}

DEN, diethylnitrosamine; AAF, acetylaminofluorene; NF- $\kappa$ B, nuclear factor kappaB; CYP450, cytchrome P450; TNF- $\alpha$, tumor necrosis factor-alpha; SOD, superoxide dismutase; MDA, malondialdehyde; CCA, cholangiocarcinoma.

TABLE 3: Beneficial effects of ginger and its constituents in GI cancer patients.

\begin{tabular}{l}
\hline Effects \\
\hline Decrease the gastric dysrhythmia and reduce the delayed nausea of chemotherapy \\
Inhibit COX and decrease PGE2 concentrations in colorectal cancer \\
Decrease the incidence and multiplicity of adenomas \\
Increase the lymphocyte counts in colorectal cancer patients \\
Reduce proliferation (hTERT, MIB-1) and differentiation (p21waf1/cip1) in colon cancer \\
Decrease the hTERT, MIB-1, and Bax expression in the whole crypts of colon \\
Decrease COX-1 protein expression in participants at increased risk for colorectal cancer \\
Decrease the mean percent change in PGE-2 and 5-HETE levels in colorectal cancer \\
Inhibit CYP450, 1-aminobenzotriazole, and aldo-keto reductase in human liver microsomes \\
Prevent the formation of M14 and M15 and $18 \beta$-glycyrrhetinic acid in human liver microsomes
\end{tabular}

4.1. Gastric Cancer. Preclinical studies have shown that ginger extract and its constituents possess chemopreventive and antineoplastic properties in gastric cancer. In vitro study showed that 6-gingerol induces apoptosis of gastric cancer cells. It facilitates TNF-related apoptosis-inducing ligand- (TRAIL-) induced apoptosis by increasing caspase$3 / 7$ activation. The induction of apoptosis by 6 -gingerol was mediated through downregulation of cytosolic inhibitor of apoptosis (cIAP)-1 and inhibiting TRAIL-induced nuclear factor-kappaB (NF- $\kappa \mathrm{B})$ activation. Besides 6-gingerol, 6shogaol also reduced the viability of gastric cancer cells by damaging microtubules [30]. When ginger extract was given to Sprague-Dawley rats having acetic acid-induced ulcers, it significantly reduced the gastric ulcer area. Ginger extract 
also attenuated elevated activities of xanthine oxidase and myeloperoxidase, as well as malondialdehyde (MDA) level in the ulcerated mucosa. Thus, ginger extract promotes ulcer healing by acting as an antioxidant and prevents gastric mucosal damage [46].

It is also reported to be effective in ameliorating the side effects of conventional therapeutic agents including $\gamma$-radiation, doxorubicin, and cisplatin by regulating $\mathrm{P}$ glycoprotein [67]. Thus ginger extract exhibits chemosensitizing effects in certain neoplastic cells in vitro and in vivo. In support of this, another study showed that ginger reverses cisplatin-induced delay in gastric emptying indicating that ginger acts as an antiemetic for cancer chemotherapy [47]. Thus, it may be useful in improving the gastrointestinal side effects of cancer chemotherapy. Besides ginger, zerumbone (a sesquiterpene) derived from a subtropical ginger Zingiber zerumbet Smith was also reported to have antitumor and antiinflammatory properties in different cancers. In gastric cancer cell lines, zerumbone inhibited cell proliferation, VEGF expression, and NF- $\kappa \mathrm{B}$ activation [28]. Thus, zerumbone acts as an antiangiogenic and antitumor drug in the treatment of gastric cancer.

4.2. Pancreatic Cancer. Ginger and its constituents are also effective against pancreatic cancer. Park et al. [27] have shown that 6-gingerol inhibits the growth of pancreatic cancer HPAC and BxPC-3 cells through cell cycle arrest at G1 phase and independent of p53 status. Further they found that 6-gingerol decreased both cyclin A and cyclindependent kinase (Cdk) expression followed by reduction in retinoblastoma $(\mathrm{Rb})$ phosphorylation and blocking of $S$ phase entry [27]. Another study showed that 6-gingerol regulates tight junction-related proteins and suppresses invasion and metastasis of pancreatic cancer cells. These functions of 6gingerol were mediated through NF- $\kappa \mathrm{B} /$ Snail inhibition via inhibition of the extracellular signal-regulated kinases (ERK) pathway. Thus, 6-gingerol suppresses the invasive activity of PANC-1 cells [25]. Another component of ginger, 6shogaol, triggers $\mathrm{Ca}^{2+}$ signals in the pancreatic $\beta$-cells by activating the TRPV1 channels. In fura-2 loaded single rat insulinoma (INS-1E) cells, 6-shogaol increased intracellular $\mathrm{Ca}^{2+}$ in a concentration-dependent manner. Intracellular $\mathrm{Ca}^{2+}$ increase obtained by $1 \mu \mathrm{M}$ 6-shogaol was found to be greater than that obtained by $10 \mathrm{mM}$ glucose [24].

Along with in vitro studies, animal studies showed that 6shogaol suppressed growth of pancreatic cancer and potentiated the effects of gemcitabine in suppression of tumor growth. The antiproliferation and sensitization to gemcitabine by 6 -shogaol was mediated through the suppression of NF- $\kappa \mathrm{B}$, cyclooxygenase- (COX-) 2, cyclin D1, survivin, cIAP-1, X-linked inhibitor of apoptosis protein (XIAP), Bcl2, and matrix metallopeptidase- (MMP-) 9. It also inhibited tumor growth in pancreatic cancer xenograft model. The inhibition of this tumor growth by 6-shogaol was associated with decrease in proliferation index (Ki-67) and increased apoptosis [23]. Thus, ginger component 6-shogaol exhibits antitumor activity both in vitro and in vivo.
A component of Asian ginger, zerumbone, also inhibits growth and proliferation of pancreatic cancer through different mechanisms. It has been reported that zerumbone induces apoptosis of PANC-1 cells. The induction of apoptosis was associated with upregulation of p53 and p21 proteins as well as production of reactive oxygen species (ROS) in zerumbone-treated PANC-1 cells [26]. This result indicated that zerumbone induced apoptosis of PANC-1 cells through p53 signaling pathway. Further Sung et al. [68] showed that it inhibits invasion of pancreatic tumor cells by downregulating chemokine receptor CXCR4 expression. They also showed that the zerumbone-induced downregulation of CXCR4 was due to transcriptional regulation and inhibition of NF- $\kappa \mathrm{B}$ activation [68]. In support of this study, recently Shamoto et al. [22] showed that zerumbone blocks angiogenesis of pancreatic cancer cells through the inhibition of NF- $\kappa \mathrm{B}$ and $\mathrm{NF}-\kappa \mathrm{B}$-dependent proangiogenic gene products.

4.3. Liver Cancer. In vitro studies reveal that ginger components are effective against liver cancer. In a study, 6-shogaol has been reported to induce apoptotic cell death of Mahlavu hepatoma cells via an oxidative stress-mediated caspasedependent mechanism. Glutathione (GSH) depletion has been shown to be a major contributing factor in arbitrating 6-shogaol-induced apoptosis of Mahlavu cells [20]. Recently Jeena et al. [40] showed that oral administration of ginger oil for one month increases antioxidant enzymes SOD, GSH, and glutathione reductase in blood of mice and glutathioneS-transferase, glutathione peroxidase, and SOD enzymes in liver of mice. Ginger oil also produced significant reduction in acute inflammation produced by carrageenan and dextran and formalin induced chronic inflammation [40], indicating its role in prevention of liver carcinogenesis.

Besides glutathione, ROS also have been involved in ginger extract-induced apoptosis of HepG2 hepatoma cells. Ginger extract at a dose of $250 \mu \mathrm{g} / \mathrm{mL}$ markedly changes morphology of cells including cell shrinkage and condensation of chromosomes in HepG2 cells [19]. Another study showed that 6-gingerol induced apoptosis of human HepG2 cells through lysosomal-mitochondrial axis, where cathepsin D played a crucial role in the process of apoptosis. 6-Gingerolinduced release of cathepsin D preceded ROS generation and cytochrome $\mathrm{c}$ release from mitochondria [16]. It is also reported to protect the lipid peroxidation in liver tissue homogenate/mitochondria. The protective mechanism can be correlated to the radical scavenging property of ginger extract [69]. In animal model, ginger suppresses ethionineinduced liver carcinogenesis by scavenging the free radical formation and by reducing lipid peroxidation. Thus, ginger prevents rat hepatocarcinogenesis [44].

The major components of ginger, 6-shogaol and 6gingerol, have shown to exert anti-invasive activity against hepatoma cells. Both compounds inhibited the migratory and invasive abilities of phorbol 12-myristate 13-acetate- (PMA-) treated HepG2 and PMA-untreated Hep3B cells. Further it was observed that inhibition of migration and invasion were mediated by decreased activity of MMP-9, urokinase-type plasminogen activator (uPA) and increased expression of tissue inhibitor metalloproteinase protein- (TIMP-) 1 [18]. 
Weng et al. [70] further supported their observation that 6-shogaol and 6-gingerol effectively inhibit invasion and metastasis of hepatocellular carcinoma by the inhibition of MMP-2/-9 and UPA, along with the suppression of MAPK and PI3k/Akt pathways, as well as downregulation of NF$\kappa \mathrm{B}$ and STAT3 activities. In animal models, Habib et al. [43] showed that ginger extract inhibits liver carcinogenesis in Wistar rat through the downregulation of elevated NF- $\kappa \mathrm{B}$ and TNF- $\alpha$. Thus, ginger may act as an anticancer and antiinflammatory agent, which could be helpful in prevention and treatment of liver cancer.

Besides these, ginger ingredients inhibit the development of diethylnitrosamine- (DEN-) induced premalignant phenotype in rat hepatocarcinogenesis. It has been found that long-term administration of ginger extract prevented the decrease in hepatic content of metallothionein and endostatin and the increase in the growth factors induced by the carcinogen in Wistar albino rats. It also restores the serum hepatic tumor markers in rat [41]. Another study showed that 6-shogaol induces apoptosis in human hepatocellular carcinoma cells through caspase activation and ER stress signaling by regulating unfolded protein response (UPR) sensor PERK and its downstream target eIF2 $\alpha$. In mouse SMMC-7721 xenograft model, 6-shogaol inhibited tumor growth by the activation of caspase- 3 and inactivation of eIF2 $\alpha$ [15]. Thus, PERK/eIF2 $\alpha$ pathway plays an important role in 6-shogaol-mediated ER stress and antitumorigenesis. Ginger ingredients have shown to modulate cytochrome P450 enzyme. The inhibition of CYP enzymes by ginger extract was more than its active components, gingerols [32]. Thus authors highlight the importance of consuming whole foods over active constituents.

Zerumbone was also reported to induce phase II detoxification enzymes in cultured rat normal liver epithelial cell line. In addition, it induces glutathione S-transferase in RL34 cells and it exhibits antioxidant effects by inducing nuclear localization of the transcription factor, nuclear factor(erythroid-derived 2) like 2 (Nrf2) that binds to antioxidant response element (ARE) of the phase II enzyme genes. Thus, authors concluded that zerumbone acts as a potential activator of the Nrf2/ARE-dependent detoxification pathway that provides a new insight into cancer prevention [21]. Zerumbone has also shown to exert antitumorigenic effect in rat liver induced by DEN and 2-acetylaminofluorene. This antihepatocarcinogenic effect of zerumbone was found to be associated with suppression of PCNA and inhibition of a number of apoptotic liver cells by increased Bax and decreased Bcl-2 protein expression [42]. Thus, zerumbone has a great potential for the treatment of liver cancers.

4.4. Colorectal Cancer. Anticancer activities of ginger against colorectal cancer have been well documented. Numerous in vitro studies showed that ginger and its active components inhibit growth and proliferation of colorectal cancer cells. In a study, 6-gingerol inhibited growth of colon cancer HCT116 cells. The suppression of tumor growth was found to be linked with the inhibition of leukotriene A4 hydrolase activity, which was further confirmed by in silico approach [71]. Besides these, various other mechanisms were reported to be involved in 6-gingerol-induced cell growth inhibition and apoptosis in human colorectal cancer cells. These include protein degradation as well as downregulation of cyclin D1, NAG-1 beta-catenin, PKCepsilon, and GSK-3 $\beta$ pathways [35]. Radhakrishnan et al. [72] reported that the anticancer activity of 6-gingerol could be associated with the inhibition of ERK1/2/JNK/AP-1 pathway.

Whole ginger extract also prevent the primary stage of colon carcinogenesis. Administration of ginger extract to the mice pretreated with carcinogen 1,2-dimethylhydrazine (DMH) inhibited the levels of fecal bile acids, neutral sterols, tissue cholesterol, HMG CoA reductase, free fatty acids, triglycerides, phospholipase A, and phospholipase C [48]. Thus, ginger supplementation reduced the risk of colon cancer markedly by virtue of its hypolipidemic and antioxidative effects. Ginger extract not only inhibits carcinogenesis of colorectal cancer cells but also enhances the anticancer effects of chemotherapeutic drug 5-fluorouracil. It has also shown that ginger extract synergistically increases the apoptotic efficacy of Gelam honey [33]. As in vitro, 6-gingerol effectively suppresses tumor growth in nude mice [71].

For improving the colon cancer therapeutic efficiency of ginger extract, a multiparticulate system (ginger extract loaded with coated alginate beads) has been designed. Preclinical evaluation against $\mathrm{DMH}$-induced colon cancer in male Wistar rats showed that this bead has significantly better recession of the cancers compared to free ginger extract [45]. Cysteine-conjugated shogaols have also been reported to cause death of colon cancer cells through the activation of the mitochondrial apoptotic pathway [73]. Hexahydrocurcumin extracted from ginger was also found to be cytotoxic to colorectal cancer cells. It has been observed that treatment of SW480 colon cancer cells with hexahydrocurcumin $(100 \mu \mathrm{M})$ resulted in apoptosis [74], indicating its potential as anticancer agent. Besides ginger rhizome, exposure of ginger leaf extract exhibited reduced cell viability and induced apoptosis to human colorectal cancer HCT116, SW480, and LoVo cells. This anticancer activity of ginger leaf extract was attributed to the increased expression of ATF3 through ERK1/2 activation in human colorectal cancer cells [75]. Another compound zerumbone, a sesquiterpene from the edible ginger (Zingiber zerumbet Smith), has been shown to enhance the radiosensitivity of colon cancer cells. It enhanced radiation-induced DNA damage and inhibited nuclear expression of DNA repair proteins ataxia-telangiectasia mutated (ATM) and DNAPKcs [76].

\section{Cholangiocarcinoma}

In vitro studies showed that ginger has a promising anticancer activity against cholangiocarcinoma. Crude ethanolic extract of ginger induces cytotoxicity and antioxidant activities in cholangiocarcinoma cells. Upregulation of MDR1 and MRP3 genes was also observed by the exposure to ginger extract [77]. Using cholangiocarcinoma (KMC-1) cell line, Thatte et al. [38] reported that ginger is capable of inducing programmed cell death. In animals, intragastric treatment of 
ginger increases survival time and rate of animals bearing carcinogen-induced tumors [77]. In nude mouse xenograft model bearing cholangiocarcinoma tumor, ginger extract also inhibited growth of tumor and exhibited anticarcinogenic property [37]. Thus, ginger can be considered as one of the promising chemotherapeutics agents for the treatment of cholangiocarcinoma.

\section{Clinical Studies of Ginger against GI Cancer}

Besides preclinical studies, clinical studies revealed that ginger has potential for the prevention and treatment of different GI related disorders (Table 3). Study in human subjects showed that ginger delays the nausea which is stimulated during chemotherapy. In this clinical study, patients with cancer receiving chemotherapy were given normal diet, protein drink with ginger, and additional high protein with ginger twice daily. They found that protein meals with ginger reduced and delayed nausea due to chemotherapy and reduced the use of antiemetic medications [51].

In a randomized clinical study 20 subjects at increased risk for colorectal cancer were included and the patients were given $2.0 \mathrm{~g} /$ days ginger or placebo for 28 days. Colon biopsies were obtained to determine the levels of prostaglandin (PGE)-2, leukotriene B4 (LTB4), 13-hydroxyoctadecadienoic acids, and 5-, 12-, and 15-hydroxyeicosatetraenoic acids. They found that although ginger did not decrease eicosanoid levels in people at increased risk for colorectal cancer, however, it was both tolerable and safe [52]. Earlier in a phase II study, Zick et al. [57] have shown no significant difference in eicosanoids level in 30 people at normal risk for colorectal cancer. However, they found a significant decrease in PGE2 and 5-hydroxyeicosatetraenoic acid (HETE) and a trend toward significant decrease in 12HETE and 15-HETE normalized to free arachidonic acid [57]. Another study on 66 colorectal cancer patients receiving chemotherapy has shown that massage with ginger and coconut oil improved cellular immunity of these patients. They found that this aromatherapy with massage boost lymphocyte number by $11 \%$. It also decreased fatigue, presenting symptom, pain, and stress in cancer patients [53].

In another pilot, randomized control trial with 20 patients at increased risk for colorectal cancer, ginger ( $2 \mathrm{~g}$ for 28 days) supplementation was also found to reduce the proliferation of normal-appearing colorectal epithelium and increased apoptosis and differentiation of the crypts. This beneficial effect of ginger was found to be associated with downregulation of Bax, human telomerase reverse transcriptase (hTERT), and MIB-1, while p21 and Bcl-2 expression remained relatively unchanged [55]. Ginger has been reported to have antiinflammatory activities as observed in a study with 30 normal participants and 20 participants at increased risk for colorectal cancer. It has been observed that ginger significantly lowers COX-1 protein expression in participants at increased risk for colorectal cancer but not in the participants at normal risk. However, ginger did not alter 15- hydroxyprostaglandin dehydrogenase $(\mathrm{PGDH})$ protein expression in either increased or normal-risk participants [56]. These results indicate chemopreventive potential of ginger against colorectal cancer.

\section{Molecular Targets}

Ginger and its components have been shown to modulate a wide range of signaling molecules (Figure 3). Ginger may upregulate or downregulate the gene expressions, depending on the target and cellular context. Ginger extract increases antioxidant enzymes including GSH, SOD, and glutathione peroxidase [40]. Component of Asian ginger oil also targets to increase the phase II detoxification enzymes as well as nuclear localization of Nrf2/ARE [21]. A number of targets of ginger and its components have been documented in different cancer models. These include transcription factors, enzymes, inflammatory mediators, protein kinases, drug resistance proteins, adhesion molecules, growth factors receptors, cellcycle regulatory proteins, cell-survival proteins, chemokines, and chemokine receptors. In different GI cancers, ginger extract inhibits transcription factor NF- $\kappa \mathrm{B}$, inflammatory cytokine TNF- $\alpha$ and other enzymes and proteins, which include xanthine oxidase and myeloperoxidase, MDA, HMG CoA reductase, free fatty acids, triglycerides, phospholipase $\mathrm{A}$, and phospholipase $\mathrm{C}$. The active ingredient of ginger, particularly, 6-gingerol and 6-shogaol targets several cellular molecules that contribute to tumorigenesis, cell survival, cell proliferation, invasion, and angiogenesis. 6-Gingerol modulates NF- $\kappa$ B, STAT3, Rb, MAPK, PI3K, Akt, ERK, cIAP1, cyclin A, Cdk, cathepsin D, and caspase-3/7. Similarly, shogaol targets NF- $\kappa$ B, STAT3, MAPK, PI3k/Akt Ca ${ }^{2+}$ signals, COX-2, cyclin D1, survivin, cIAP-1, XIAP, Bcl-2, MMP9, caspase activation, ER stress, and eIF $2 \alpha$. Besides these, Asian ginger component zerumbone modulates NF- $\kappa \mathrm{B}, \mathrm{p} 53$ VEGF, p21, and CXCR4 expression. Thus these molecular targets of ginger components indicate that it may have the potential for preventing and treating the GI cancer.

\section{Conclusion}

Although the medicinal properties of ginger have been known for thousands of years, a significant number of in vitro, in vivo, and epidemiological studies further provide substantial evidence that ginger and its active compounds are effective against wide variety of human diseases including GI cancer. Ginger has been found to be effective against various GI cancers such as gastric cancer, pancreatic cancer, liver cancer, colorectal cancer, and cholangiocarcinoma. However, its anticancer effects on other GI cancers like duodenal, esophageal, anal, GI carcinoid tumor and pancreatic islet cell cancer have yet not been established. Therefore, efficacy of such potent agents on these cancers is warranted. Ginger and its polyphenols have been shown to target multiple signaling molecules that provide a basis for its use against multifactorial human diseases. Moreover, most of the known activities of ginger components are based only on in vitro and in vivo studies, except for a few clinical studies in human subjects. Therefore, more extensive and well-controlled human studies are required to demonstrate its efficacy as an anticancer agent, as it is a safe and cost-effective alternative. 


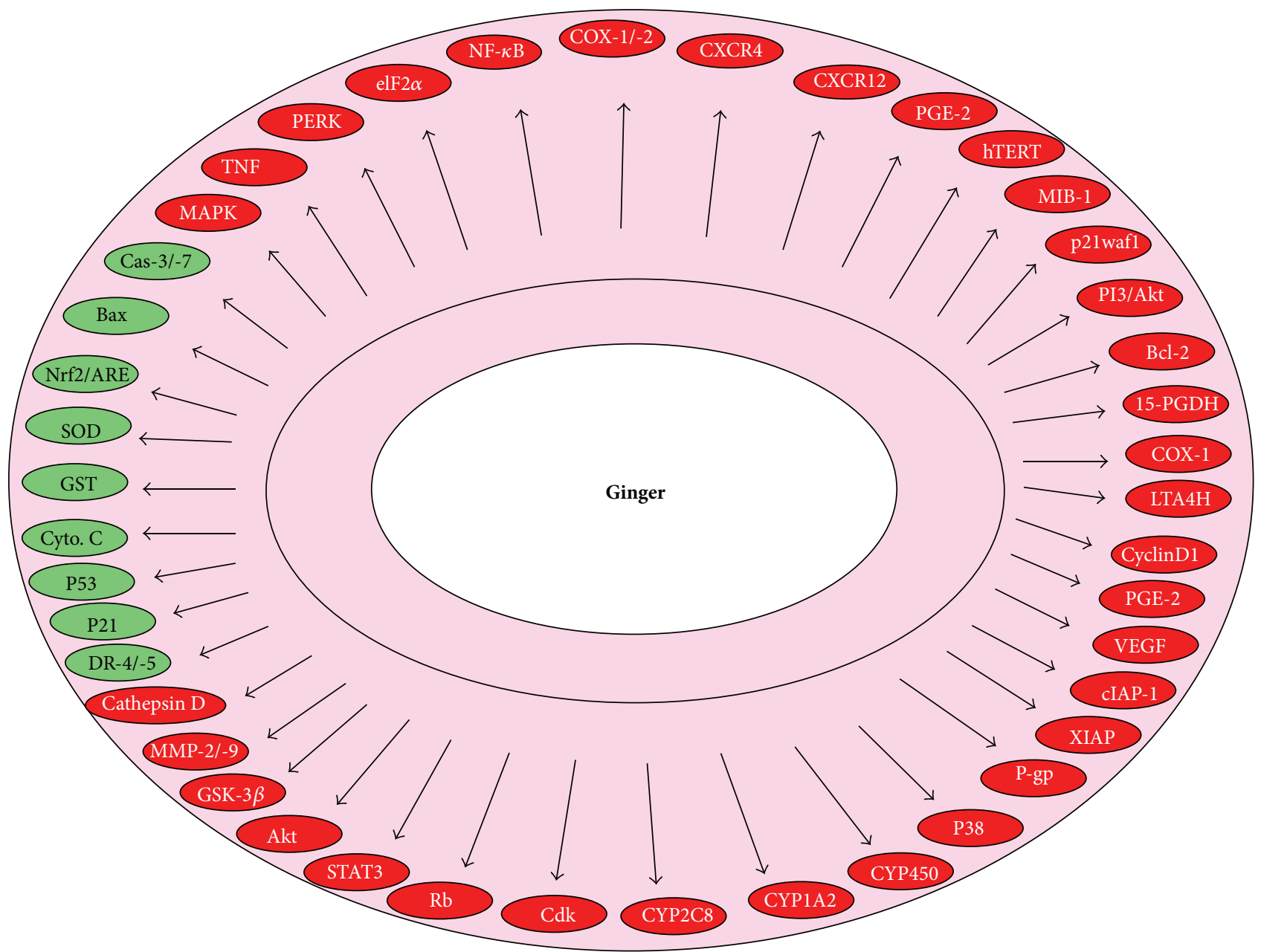

FIGURE 3: Molecular targets of ginger and its active constituents against gastrointestinal cancer.

\section{Conflict of Interests}

The authors declare that there is no conflict of interests regarding the publication of this paper.

\section{Acknowledgments}

The authors thank Dr. Sridevi Patchva of MD Anderson Cancer Center and Dr. Prachi Kaushik of Indian Institute of Technology Delhi, India, for carefully editing the paper.

\section{References}

[1] E. N. Marieb, Essentials of Human Anatomy and Physiology, Benjamin Cummings, New York, NY, USA, 8th edition, 2005.

[2] Å. Klint, G. Engholm, H. H. Storm et al., "Trends in survival of patients diagnosed with cancer of the digestive organs in the Nordic countries 1964-2003 followed up to the end of 2006," Acta Oncologica, vol. 49, no. 5, pp. 578-607, 2010.

[3] R. Siegel, C. Desantis, and A. Jemal, "Colorectal cancer statistics, 2014," CA Cancer Journal for Clinicians, vol. 64, no. 2, pp. 104117, 2014.
[4] S. Prasad, J. H. Kim, S. C. Gupta, and B. B. Aggarwal, “Targeting death receptors for TRAIL by agents designed by mother nature," Trends in Pharmacological Sciences, vol. 35, no. 10, pp. 520-536, 2014.

[5] S. Prasad, B. Sung, and B. B. Aggarwal, "Age-associated chronic diseases require age-old medicine: role of chronic inflammation," Preventive Medicine, vol. 54, pp. S29-S37, 2012.

[6] B. Sung, S. Prasad, V. R. Yadav, A. Lavasanifar, and B. B. Aggarwal, "Cancer and diet: how are they related?" Free Radical Research, vol. 45, no. 8, pp. 864-879, 2011.

[7] B. B. Aggarwal, M. E. van Kuiken, L. H. Iyer, K. B. Harikumar, and B. Sung, "Molecular targets of nutraceuticals derived from dietary spices: potential role in suppression of inflammation and tumorigenesis," Experimental Biology and Medicine, vol. 234, no. 8, pp. 825-849, 2009.

[8] M. P. A. Zeegers, R. A. Goldbohm, and P. A. Van den Brandt, "Consumption of vegetables and fruits and urothelial cancer incidence: a prospective study," Cancer Epidemiology Biomarkers and Prevention, vol. 10, no. 11, pp. 1121-1128, 2001.

[9] G. Demin and Z. Yingying, "Comparative antibacterial activities of crude polysaccharides and flavonoids from Zingiber officinale and their extraction," American Journal of Tropical Medicine, vol. 5, pp. 235-238, 2010. 
[10] R. Grzanna, L. Lindmark, and C. G. Frondoza, "Gingeran herbal medicinal product with broad anti-inflammatory actions," Journal of Medicinal Food, vol. 8, no. 2, pp. 125-132, 2005.

[11] E. Langner, S. Greifenberg, and J. Gruenwald, "Ginger: history and use," Advances in Therapy, vol. 15, no. 1, pp. 25-44, 1998.

[12] Y. Shukla and M. Singh, "Cancer preventive properties of ginger: a brief review," Food and Chemical Toxicology, vol. 45, no. 5, pp. 683-690, 2007.

[13] S. V. Nair, Ziaullah, and H. P. Rupasinghe, "Fatty acid esters of phloridzin induce apoptosis of human liver cancer cells through altered gene expression," PLoS ONE, vol. 9, no. 9, Article ID e107149, 2014.

[14] H. Chen, D. Soroka, Y. Zhu, and S. Sang, "Metabolism of ginger component [6]-shogaol in liver microsomes from mouse, rat, dog, monkey, and human," Molecular Nutrition and Food Research, vol. 57, no. 5, pp. 865-876, 2013.

[15] R. Hu, P. Zhou, Y.-B. Peng et al., “6-shogaol induces apoptosis in human hepatocellular carcinoma cells and exhibits anti-tumor activity in vivo through endoplasmic reticulum stress," PLoS ONE, vol. 7, no. 6, Article ID e39664, 2012.

[16] G. Yang, S. Wang, L. Zhong et al., "6-gingerol induces apoptosis through lysosomal-mitochondrial axis in human hepatoma G2 cells," Phytotherapy Research, vol. 26, no. 11, pp. 1667-1673, 2012.

[17] F. Peng, Q. Tao, X. Wu et al., "Cytotoxic, cytoprotective and antioxidant effects of isolated phenolic compounds from fresh ginger," Fitoterapia, vol. 83, no. 3, pp. 568-585, 2012.

[18] C.-J. Weng, C.-F. Wu, H.-W. Huang, C.-T. Ho, and G.-C. Yen, "Anti-invasion effects of 6-shogaol and 6-gingerol, two active components in ginger, on human hepatocarcinoma cells," Molecular Nutrition and Food Research, vol. 54, no. 11, pp. 16181627, 2010.

[19] V. Vijaya Padma, S. Arul Diana Christie, and K. M. Ramkuma, "Induction of apoptosis by ginger in HEp-2 cell line is mediated by reactive oxygen species," Basic and Clinical Pharmacology and Toxicology, vol. 100, no. 5, pp. 302-307, 2007.

[20] C.-Y. Chen, T.-Z. Liu, Y.-W. Liu et al., "6-Shogaol (Alkanone from Ginger) induces apoptotic cell death of human hepatoma p53 mutant mahlavu subline via an oxidative stress-mediated caspase-dependent mechanism," Journal of Agricultural and Food Chemistry, vol. 55, no. 3, pp. 948-954, 2007.

[21] Y. Nakamura, C. Yoshida, A. Murakami, H. Ohigashi, T. Osawa, and K. Uchida, "Zerumbone, a tropical ginger sesquiterpene, activates phase II drug metabolizing enzymes," FEBS Letters, vol. 572, no. 1-3, pp. 245-250, 2004.

[22] T. Shamoto, Y. Matsuo, T. Shibata et al., "Zerumbone inhibits angiogenesis by blocking NF- $\kappa \mathrm{B}$ activity in pancreatic cancer," Pancreas, vol. 43, no. 3, pp. 396-404, 2014.

[23] L. Zhou, L. Qi, L. Jiang et al., "Antitumor activity of gemcitabine can be potentiated in pancreatic cancer through modulation of TLR4/NF- $\kappa$ B signaling by 6-shogaol," The AAPS Journal, vol. 16, no. 2, pp. 246-257, 2014.

[24] P. Rebellato and M. S. Islam, "[6]-shogaol induces $\mathrm{Ca}^{2+}$ signals by activating the TRPV1 channels in the rat insulinoma INS-1E cells," Journal of the Pancreas, vol. 15, no. 1, pp. 33-37, 2014.

[25] S. O. Kim and M. R. Kim, "[6]-gingerol prevents disassembly of cell junctions and activities of MMPs in invasive human pancreas cancer cells through ERK/NF- $\kappa \mathrm{B} /$ snail signal transduction pathway," Evidence-based Complementary and Alternative Medicine, vol. 2013, Article ID 761852, 9 pages, 2013.
[26] S. Zhang, Q. Liu, Y. Liu, and H. Qiao, “Zerumbone, a Southeast Asian ginger sesquiterpene, induced apoptosis of pancreatic carcinoma cells through p53 signaling pathway," Evidence-Based Complementary and Alternative Medicine, vol. 2012, Article ID 936030, 8 pages, 2012.

[27] Y. J. Park, J. Wen, S. Bang, S. W. Park, and S. Y. Song, "[6]Gingerol induces cell cycle arrest and cell death of mutant p53expressing pancreatic cancer cells," Yonsei Medical Journal, vol. 47, no. 5, pp. 688-697, 2006.

[28] K. Tsuboi, Y. Matsuo, T. Shamoto et al., "Zerumbone inhibits tumor angiogenesis via NF- $\kappa \mathrm{B}$ in gastric cancer," Oncology Reports, vol. 31, no. 1, pp. 57-64, 2014.

[29] K. Gaus, Y. Huang, D. A. Israel, S. L. Pendland, B. A. Adeniyi, and G. B. Mahady, "Standardized ginger (Zingiber officinale) extract reduces bacterial load and suppresses acute and chronic inflammation in Mongolian gerbils infected with $\mathrm{cagA}^{+} \mathrm{Heli}_{-}$ cobacter pylori," Pharmaceutical Biology, vol. 47, no. 1, pp. 92-98, 2009.

[30] K. Ishiguro, T. Ando, O. Maeda et al., "Ginger ingredients reduce viability of gastric cancer cells via distinct mechanisms," Biochemical and Biophysical Research Communications, vol. 362, no. 1, pp. 218-223, 2007.

[31] G. B. Mahady, S. L. Pendland, G. S. Yun, Z.-Z. Lu, and A. Stoia, "Ginger (Zingiber officinale Roscoe) and the Gingerols Inhibit the Growth of Cag A+ Strains of Helicobacter pylori," Anticancer Research, vol. 23, no. 5, pp. 3699-3702, 2003.

[32] R. Mukkavilli, S. R. Gundala, C. Yang et al., "Modulation of cytochrome $\mathrm{P} 450$ metabolism and transport across intestinal epithelial barrier by ginger biophenolics," PLOS ONE, vol. 9, no. 9, Article ID e108386, 2014.

[33] L. Hakim, E. Alias, S. Makpol, W.Z. W. Ngah, N. A. Morad, and Y. A. Yusof, "Gelam honey and ginger potentiate the anti cancer effect of 5-FU against HCT 116 colorectal cancer cells," Asian Pacific Journal of Cancer Prevention, vol. 15, no. 11, pp. 46514657, 2014.

[34] M.-H. Pan, M.-C. Hsieh, J.-M. Kuo et al., "6-Shogaol induces apoptosis in human colorectal carcinoma cells via ROS production, caspase activation, and GADD 153 expression," Molecular Nutrition and Food Research, vol. 52, no. 5, pp. 527-537, 2008.

[35] S. H. Lee, M. Cekanova, and J. B. Seung, "Multiple mechanisms are involved in 6-gingerol-induced cell growth arrest and apoptosis in human colorectal cancer cells," Molecular Carcinogenesis, vol. 47, no. 3, pp. 197-208, 2008.

[36] S. Yodkeeree, B. Sung, P. Limtrakul, and B. B. Aggarwal, "Zerumbone enhances TRAIL-induced apoptosis through the induction of death receptors in human colon cancer cells: evidence for an essential role of reactive oxygen species," Cancer Research, vol. 69, no. 16, pp. 6581-6589, 2009.

[37] T. Plengsuriyakarn, V. Viyanant, V. Eursitthichai et al., "Anticancer activities against cholangiocarcinoma, toxicity and pharmacological activities of Thai medicinal plants in animal models," BMC Complementary and Alternative Medicine, vol. 12, article 23, 2012.

[38] U. Thatte, S. Bagadey, and S. Dahanukar, "Modulation of programmed cell death by medicinal plants," Cellular and Molecular Biology, vol. 46, no. 1, pp. 199-214, 2000.

[39] C.-T. Liu, R. Raghu, S.-H. Lin et al., "Metabolomics of ginger essential oil against alcoholic fatty liver in mice," Journal of Agricultural and Food Chemistry, vol. 61, no. 46, pp. 11231-11240, 2013.

[40] K. Jeena, V. B. Liju, and R. Kuttan, "Antioxidant, antiinflammatory and antinociceptive activities of essential oil from 
ginger," Indian Journal of Physiology and Pharmacology, vol. 57, no. 1, pp. 51-62, 2013.

[41] M. A. Mansour, S. A. Bekheet, S. S. Al-Rejaie et al., "Ginger ingredients inhibit the development of diethylnitrosoamine induced premalignant phenotype in rat chemical hepatocarcinogenesis model," BioFactors, vol. 36, no. 6, pp. 483-490, 2010.

[42] M. M. E. Taha, A. B. Abdul, R. Abdullah, T. A. T. Ibrahim, S. I. Abdelwahab, and S. Mohan, "Potential chemoprevention of diethylnitrosamine-initiated and 2-acetylaminofluorenepromoted hepatocarcinogenesis by zerumbone from the rhizomes of the subtropical ginger (Zingiber zerumbet)," ChemicoBiological Interactions, vol. 186, no. 3, pp. 295-305, 2010.

[43] S. H. M. Habib, S. Makpol, N. A. A. Hamid, S. Das, W. Z. W. Ngah, and Y. A. M. Yusof, "Ginger extract (Zingiber officinale) has anti-cancer and anti-inflammatory effects on ethionineinduced hepatoma rats," Clinics (Sao Paulo), vol. 63, no. 6, pp. 807-813, 2008.

[44] Y. A. M. Yusof, N. Ahmad, S. Das, S. Sulaiman, and N. A. Murad, "Chemopreventive efficacy of ginger (Zingiber officinale) in ethionine induced rat hepatocarcinogenesis," African Journal of Traditional, Complementary and Alternative Medicines, vol. 6, no. 1, pp. 87-93, 2009.

[45] P. K. Deol and I. P. Kaur, "Improving the therapeutic efficiency of ginger extract for treatment of colon cancer using a suitably designed multiparticulate system," Journal of Drug Targeting, vol. 21, no. 9, pp. 855-865, 2013.

[46] J. K. Ko and C. C. Leung, "Ginger extract and polaprezinc exert gastroprotective actions by anti-oxidant and growth factor modulating effects in rats," Journal of Gastroenterology and Hepatology (Australia), vol. 25, no. 12, pp. 1861-1869, 2010.

[47] S. S. Sharma and Y. K. Gupta, "Reversal of cisplatin-induced delay in gastric emptying in rats by ginger (Zingiber officinale)," Journal of Ethnopharmacology, vol. 62, no. 1, pp. 49-55, 1998.

[48] V. Manju, P. Viswanathan, and N. Nalini, "Hypolipidemic effect of ginger in 1,2-dimethyl hydrazine-induced experimental colon carcinogenesis," Toxicology Mechanisms and Methods, vol. 16, no. 8, pp. 461-472, 2006.

[49] V. Manju and N. Nalini, "Effect of ginger on bacterial enzymes in 1,2-dimethylhydrazine induced experimental colon carcinogenesis," European Journal of Cancer Prevention, vol. 15, no. 5, pp. 377-383, 2006.

[50] N. Yoshimi, A. Wang, Y. Morishita et al., "Modifying effects of fungal and herb metabolites on azoxymethane-induced intestinal carcinogenesis in rats," Japanese Journal of Cancer Research, vol. 83, no. 12, pp. 1273-1278, 1992.

[51] M. E. Levine, M. G. Gillis, S. Y. Koch, A. C. Voss, R. M. Stern, and K. L. Koch, "Protein and ginger for the treatment of chemotherapy-induced delayed nausea," Journal of Alternative and Complementary Medicine, vol. 14, no. 5, pp. 545-551, 2008.

[52] S. M. Zick, D. K. Turgeon, J. Ren et al., "Pilot clinical study of the effects of ginger root extract on eicosanoids in colonic mucosa of subjects at increased risk for colorectal cancer," Molecular Carcinogenesis, 2014.

[53] S. Khiewkhern, S. Promthet, A. Sukprasert, W. Eunhpinitpong, and P. Bradshaw, "Effectiveness of aromatherapy with light thai massage for cellular immunity improvement in colorectal cancer patients receiving chemotherapy," Asian Pacific Journal of Cancer Prevention, vol. 14, no. 6, pp. 3903-3907, 2013.

[54] G. D. Stoner, "Ginger: is it ready for prime time?" Cancer Prevention Research, vol. 6, no. 4, pp. 257-262, 2013.

[55] J. Citronberg, R. Bostick, T. Ahearn et al., "Effects of ginger supplementation on cell-cycle biomarkers in the normal-appearing colonic mucosa of patients at increased risk for colorectal cancer: results from a pilot, randomized, and controlled trial," Cancer Prevention Research, vol. 6, no. 4, pp. 271-281, 2013.

[56] Y. Jiang, D. K. Turgeon, B. D. Wright et al., "Effect of ginger root on cyclooxygenase-1 and 15-hydroxyprostaglandin dehydrogenase expression in colonic mucosa of humans at normal and increased risk for colorectal cancer," European Journal of Cancer Prevention, vol. 22, no. 5, pp. 455-460, 2013.

[57] S. M. Zick, D. K. Turgeon, S. K. Vareed et al., "Phase II study of the effects of ginger root extract on eicosanoids in colon mucosa in people at normal risk for colorectal cancer," Cancer Prevention Research, vol. 4, no. 11, pp. 1929-1937, 2011.

[58] V. E. Tyler, The Therapeutic Use of Phytomedicinals, Pharmaceutical Products Press, New York, NY, USA, 1994.

[59] B. H. Ali, G. Blunden, M. O. Tanira, and A. Nemmar, "Some phytochemical, pharmacological and toxicological properties of ginger (Zingiber officinale Roscoe): a review of recent research," Food and Chemical Toxicology, vol. 46, no. 2, pp. 409-420, 2008.

[60] V. S. Govindarajan, "Ginger-chemistry, technology, and quality evaluation. Part 1," Critical reviews in food science and nutrition, vol. 17, no. 1, pp. 1-96, 1982.

[61] M. Harold, On Food and Cooking: The Science and Lore of the Kitchen, Scribner, New York, NY, USA, 2nd edition, 2004.

[62] I. Sasidharan and A. Nirmala Menon, "Comparative chemical composition and antimicrobial activity fresh \& dry ginger oils (zigiber officinale roscoe)," International Journal of Current Pharmaceutical Research, vol. 2, pp. 40-43, 2010.

[63] S. Holtmann, A. H. Clarke, H. Scherer, and M. Hohn, "The antimotion sickness mechanism of ginger. A comparative study with placebo and dimenhydrinate," Acta Oto-Laryngologica, vol. 108, no. 3-4, pp. 168-174, 1989.

[64] W. Qidwai, S. R. Alim, R. H. Dhanani, S. Jehangir, A. Nasrullah, and A. Raza, "Use of folk remedies among patients in Karachi Pakistan," Journal of Ayub Medical College, Abbottabad, vol. 15, no. 2, pp. 31-33, 2003.

[65] P. Alam, "Densitometric HPTLC analysis of 8-gingerol in Zingiber officinale extract and ginger-containing dietary supplements, teas and commercial creams," Asian Pacific Journal of Tropical Biomedicine, vol. 3, no. 8, pp. 634-638, 2013.

[66] K. Srinivasan, "Antioxidant potential of spices and their active constituents," Critical Reviews in Food Science and Nutrition, vol. 54, no. 3, pp. 352-372, 2014.

[67] M. M. Pereira, R. Haniadka, P. P. Chacko, P. L. Palatty, and M. S. Baliga, "Zingiber officinale Roscoe (ginger) as an adjuvant in cancer treatment: a review," Journal of B.U.ON., vol. 16, no. 3, pp. 414-424, 2011.

[68] B. Sung, S. Jhurani, S. A. Kwang et al., "Zerumbone downregulates chemokine receptor CXCR4 expression leading to inhibition of CXCL12-induced invasion of breast and pancreatic tumor cells," Cancer Research, vol. 68, no. 21, pp. 8938-8944, 2008.

[69] T. A. Ajith, "Ameliorating reactive oxygen species-induced in vitro lipid peroxidation in brain, liver, mitochondria and DNA damage by Zingiber officinale Roscoe," Indian Journal of Clinical Biochemistry, vol. 25, no. 1, pp. 67-73, 2010.

[70] C.-J. Weng, C.-P. Chou, C.-T. Ho, and G.-C. Yen, "Molecular mechanism inhibiting human hepatocarcinoma cell invasion by 6-shogaol and 6-gingerol," Molecular Nutrition and Food Research, vol. 56, no. 8, pp. 1304-1314, 2012.

[71] C.-H. Jeong, A. M. Bode, A. Pugliese et al., "[6]-Gingerol suppresses colon cancer growth by targeting leukotriene $\mathrm{A}_{4}$ hydrolase," Cancer Research, vol. 69, no. 13, pp. 5584-5591, 2009. 
[72] E. K. Radhakrishnan, S. V. Bava, S. S. Narayanan et al., "[6]Gingerol induces caspase-dependent apoptosis and prevents PMA-induced proliferation in colon cancer cells by inhibiting MAPK/AP-1 signaling," PLoS ONE, vol. 9, no. 8, Article ID e104401, 2014.

[73] J. Fu, H. Chen, D. N. Soroka, R. F. Warin, and S. Sang, "Cysteineconjugated metabolites of ginger components, shogaols, induce apoptosis through oxidative stress-mediated p53 pathway in human colon cancer cells," Journal of Agricultural and Food Chemistry, vol. 62, no. 20, pp. 4632-4642, 2014.

[74] C.-Y. Chen, W.-L. Yang, and S.-Y. Kuo, "Cytotoxic activity and cell cycle analysis of hexahydrocurcumin on SW 480 human colorectal cancer cells," Natural Product Communications, vol. 6, no. 11, pp. 1671-1672, 2011.

[75] G. Park, J. Park, H. Song et al., "Anti-cancer activity of Ginger (Zingiber officinale) leaf through the expression of activating transcription factor 3 in human colorectal cancer cells," BMC Complementary and Alternative Medicine, vol. 14, no. 1, article 408, 2014.

[76] A. Deorukhkar, N. Ahuja, A. L. Mercado et al., "Zerumbone increases oxidative stress in a thiol-dependent ROSindependent manner to increase DNA damage and sensitize colorectal cancer cells to radiation," Cancer Medicine, vol. 4, no. 2, pp. 278-292, 2015.

[77] T. Plengsuriyakarn, V. Viyanant, V. Eursitthichai et al., "Cytotoxicity, toxicity, and anticancer activity of Zingiber officinale roscoe against cholangiocarcinoma," Asian Pacific Journal of Cancer Prevention, vol. 13, no. 9, pp. 4597-4606, 2012. 


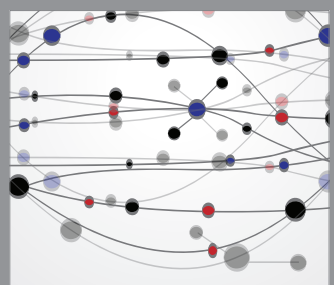

The Scientific World Journal
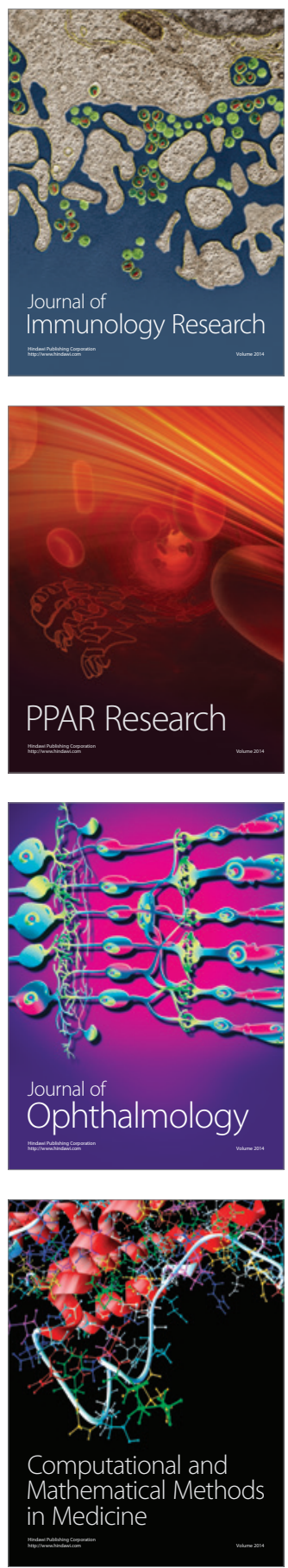

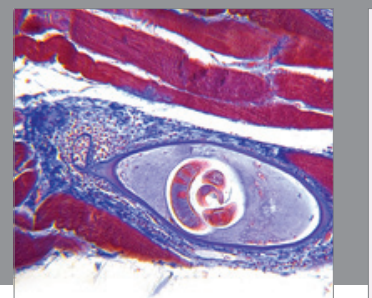

Gastroenterology

Research and Practice
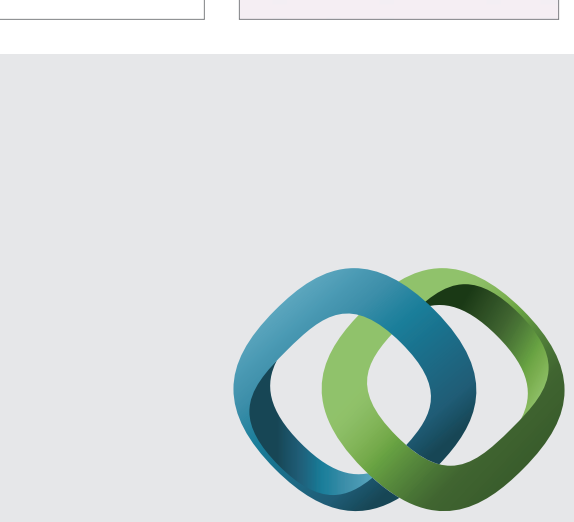

\section{Hindawi}

Submit your manuscripts at

http://www.hindawi.com
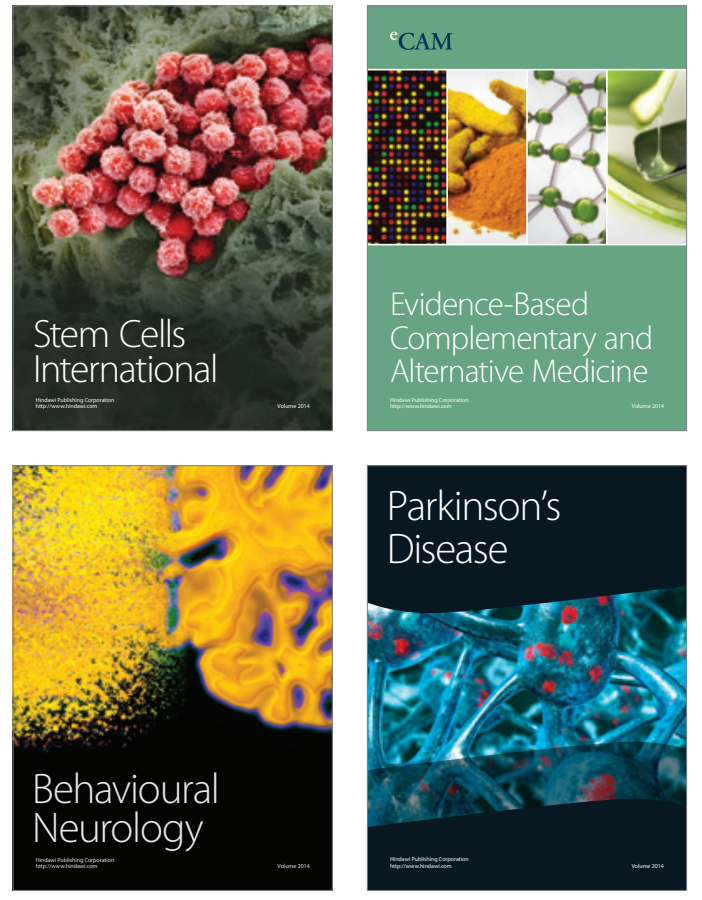
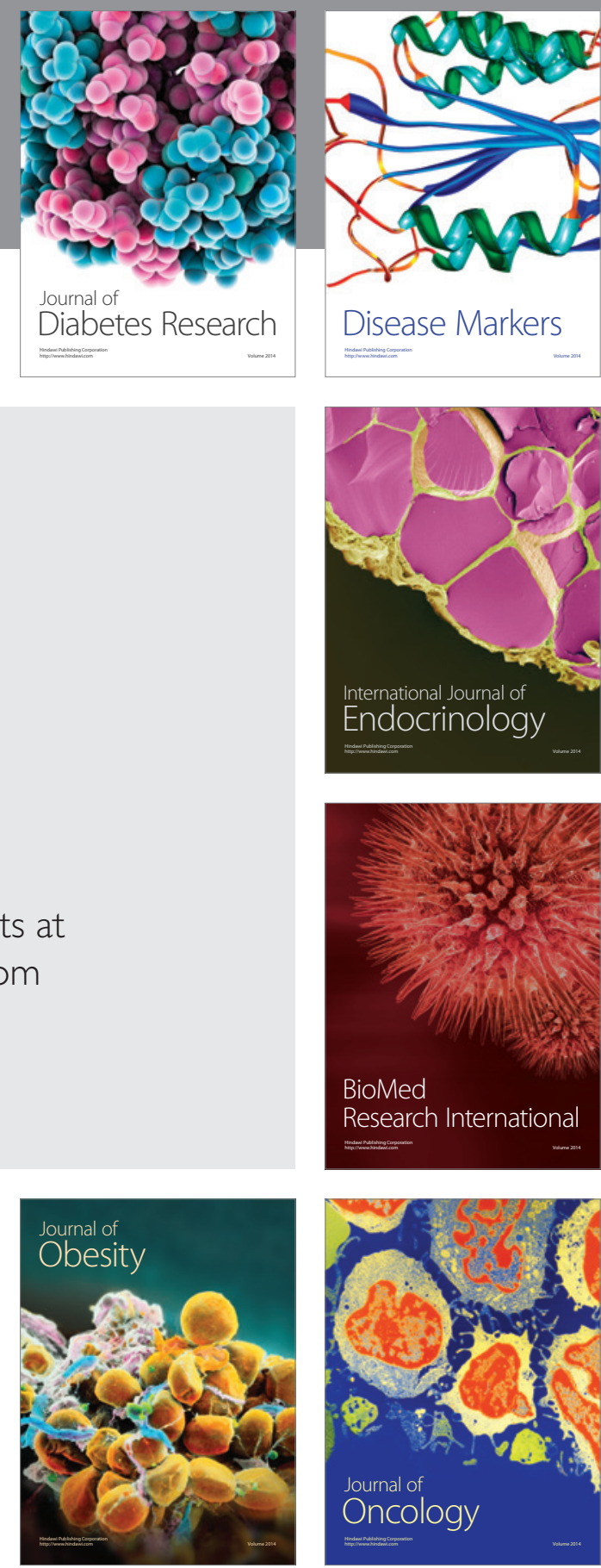

Disease Markers
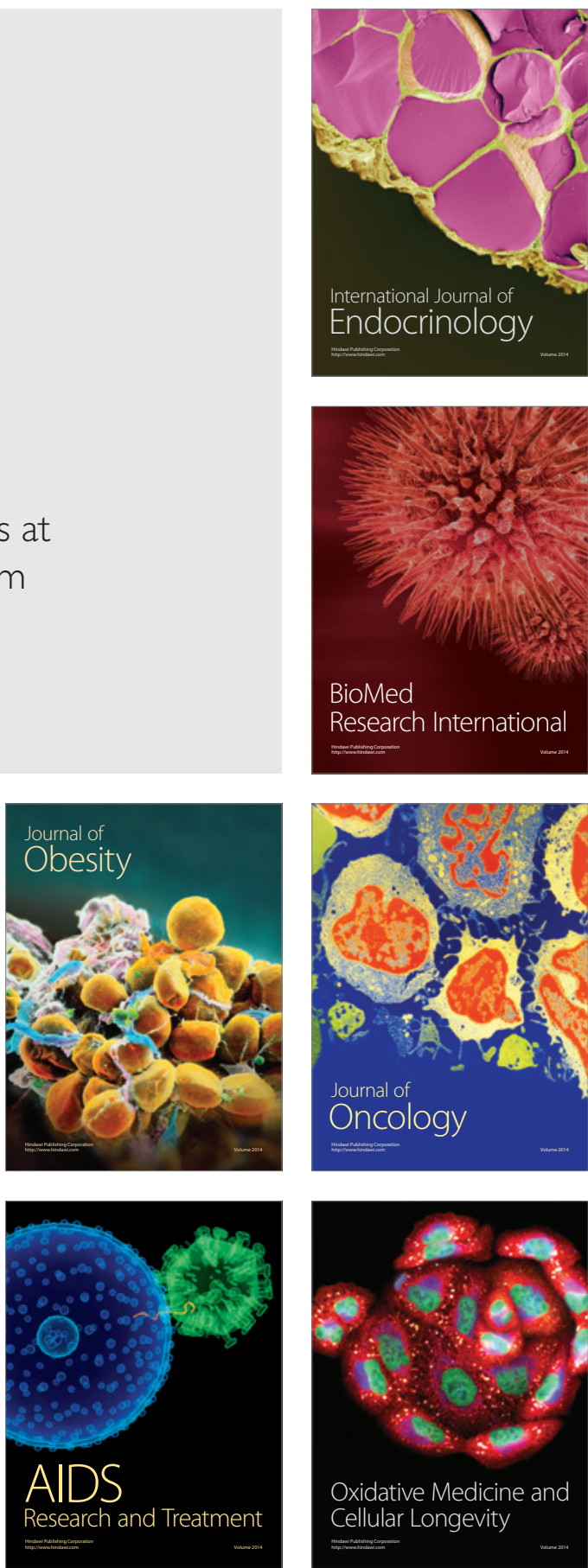